\title{
A Mating-Induced Protein of Phytophthora infestans Is a Member of a Family of Elicitors with Divergent Structures and Stage-Specific Patterns of Expression
}

\author{
Anna-Liisa Fabritius and Howard S. Judelson \\ Department of Plant Pathology, University of California, Riverside, CA 92521 U.S.A. \\ Submitted 3 March 2003. Accepted 12 June 2003.
}

Five members of an elicitor-like gene family from $P h y$ tophthora infestans were examined. The family was identified through the analysis of $M 81$, a mating-induced gene. The predicted $M 81$ product resembled a $42-\mathrm{kDa} P$. sojae glycoprotein known to elicit defense reactions in plants, including a host of $P$. infestans, potato. M81 was the most structurally and functionally divergent of the $P$. infestans genes compared with the $P$. sojae sequence. M81 lacked elicitor activity, had the lowest protein identity (47\%), displayed mating-specific transcription, and had a novel $\mathrm{C}$ terminal domain. The latter contained a 30-residue prolineand threonine-rich motif, which, remarkably, was tandemly repeated 24 to 36 times in different alleles. $M 81 C$, $M 81 D$, and $M 81 E$ better resembled the $P$. sojae protein based on amino acid identity (63 to $75 \%)$ and conserved elicitor activity. $M 81 C$ and $M 81 D$ mRNA accumulated only during zoosporogenesis, while $M 81 E$ expression was restricted to hyphae. $M 81 B$, an apparent pseudogene, was physically linked to $M 81$. The protein products of each gene were predicted to be extracellular transglutaminases ranging in size from 436 to 1,607 amino acids. Genes with an elicitor, proline- and threonine-rich repeat, and both elicitor and repeat domains were widely distributed throughout Phytophthora infestans. These findings help explain the natural functions of elicitors in pathogen biology and plant-microbe interactions.

Additional keywords: oomycete, oosporogenesis, potato late blight.

Oomycetes, fungi, bacteria, viruses, and nematodes each secrete or have as a surface component various glycans, fatty acids, and proteins that trigger defense responses in plants (Boller 1995). While the ability to perceive such elicitors enhances plant survival, their production ostensibly diminishes pathogen fitness. The resulting paradox is why such elicitors were not modified or lost during evolution. One explanation is that changes in elicitors do occur but are balanced by the development in plants of new recognition specificities, as in gene-for-gene systems (Ellis et al. 2000).

Current address for A.-L. Fabritius: Department of Applied Biology, 00014 University of Helsinki, Finland.

Corresponding author: H. S. Judelson: Telephone: 909-787-4199; Fax: 909-787-4294; E-mail: howard.judelson@ucr.edu.

Nucleotide and amino acid sequence data are available in the GenBank database as accession numbers AY237402 to AY237406.
Another theory suggests that maintaining elicitors stabilizes the evolutionary equilibrium between host and pathogen, ensuring that both survive (Kirchner and Roy 2000). A further model for the persistence of elicitors is that plants evolved to recognize factors essential for the normal growth of pathogens, which are accordingly difficult to modify (Pryor 1987). This is a component of the pathogen-associated molecular pattern concept, which was first developed to explain the innate immune response of insects and vertebrates (Ozinsky et al. 2000) and later adapted to plants (Nuernberger and Brunner 2002).

The molecular functions of general or race-specific elicitors in the life cycles of plant pathogens are understood in only a few cases. These include bacterial flagellins (Felix et al. 1999) and cold shock proteins (Felix and Boller 2003), some bacterial avirulence proteins that enhance the leakage of nutrients from plants (Gabriel 1999; Lauge and De Wit 1998), and oomycete elicitins, which are sterol carrier proteins (Ponchet et al. 1999). However, the inactivation of genes for many elicitors often has little effect on growth, development, or pathogenic fitness (Gabriel 1999; Kamoun et al. 1998; Van Kan et al. 1991; Vivian and Gibbon 1997).

Additional insight into the normal roles of elicitors came from a recent study of sexual development in the oomycete Phytophthora infestans, the cause of potato late blight. That study was performed to understand how A1 and A2 mating types interact to form oospores, which are significant in Phytophthora diseases as overwintering inoculum and a source of new genotypes (Erwin and Ribeiro 1996; Goodwin et al. 1998). Two genes expressed only during sexual development resembled elicitors (Fabritius et al. 2002). M25 encoded a member of the elicitin family (Ponchet et al. 1999), while the predicted product of $M 81$ resembled a $42-\mathrm{kDa}$ glycoprotein elicitor from $P$. sojae. The $P$. sojae protein induces defense reactions in nonhosts including parsley and potato and has transglutaminase activity, and only a 13-amino acid peptide from the protein, Pep-13, is required for elicitor function (Brunner et al. 2002; Sacks et al. 1995).

Considering that Pep-13 induces defenses in a host of $P$. infestans, it is important to understand the structure and expression of its relative, M81. Here, we report that $M 81$ is a member of a family of at least five genes in $P$. infestans that encode proteins with diverse structures, elicitor activities, and patterns of expression. While the original M81 gene is transcribed only during mating, other family members are expressed only in vegetative hyphae or zoospore stages. The proteins had features suggestive of roles in cell wall modification, which helps illuminate the function of the elicitor family in the normal life cycles of oomyceteous plant pathogens. 


\section{RESULTS}

Determining the structure of the full $M 81$ gene.

Our prior study identified a 250-nt cDNA fragment of a mating-induced gene, M81, by subtraction cloning (Fabritius et al. 2002). Starting from that short cDNA, the structure of the entire gene was elucidated by sequencing a genomic clone, related cDNA clones from the subtraction, and the products of reverse transcription-polymerase chain reaction (RT-PCR) and rapid amplification of cDNA ends (RACE) reactions. The principal objectives of this were predicting the structure of the gene's protein product and determining the basis of a multiband phenotype in RNA blots. The M81 cDNA detected 5.1and $4.1-\mathrm{kb}$ bands in poly $\mathrm{A}^{+} \mathrm{RNA}$ from matings of isolates 8811 and 618 , only the 5.1-kb band in self-fertile strain 6.11, and no signal in nonmating cultures of A1 or A2 strains (Fig. 1). To help interpret data shown later, it should be noted that only the 5.1-kb band is observed in blots of total RNA, since the 4.1-kb M81 mRNA and 18S ribosomal RNA comigrate and compete for binding to the hybridization membrane (Fig. 1).

The gene appeared to be single copy based on low-stringency hybridizations of the 250-nt M81 cDNA to genomic DNA of 8811 and 618 (Fig. 2A). A polymorphism was detected in each digest, however, which, as described later, provided the initial evidence that many isolates were heterozygotes of large and small alleles of $M 81$, which resulted in the 5.1- and 4.1-kb transcripts. Also discussed later is how probes from other regions of $M 81$ revealed that the gene was a member of a family.

M81 also appeared to be single copy in strain 2.20, the source of a bacterial artificial chromosome (BAC) clone used for sequencing the entire gene in hybridizations using the 250nt cDNA (Fig 2B). M81-containing BstXI and PstI fragments from the $\mathrm{BAC}$ and 2.20 were identical in size, which indicated that the BAC was not rearranged. This is an important point, since $M 81$ has an unusual structure that is unstable in most plasmids, as described later.

Overall features of the allele of $M 81$ from the BAC are shown in Figure 3A. The primary transcript of 5,104 nt contains a 4,821 -nt open reading frame that is preceded by a 68 -nt untranslated $5^{\prime}$ leader and followed by $216 \mathrm{nt}$ of untranslated $3^{\prime}$ sequences. Transcription began within the sequence GCTCACTTTGAAATCC, which matches a motif in many oomycete

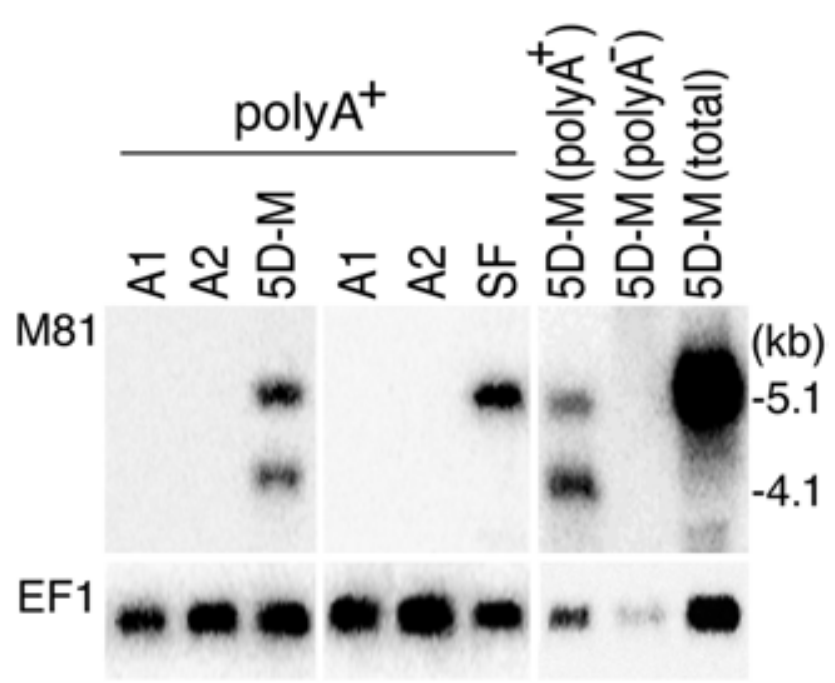

Fig. 1. Transcription of $M 81$ in Phytophthora infestans. Blots were hybridized with the 250-nt M81 cDNA (M81) or a probe for elongation factor-1 (EF1) as a control. The blot shown is RNA from 5-day-old cultures of 8811 (A1), 618 (A2), $8811 \times 618$ matings (5D-M), and self-fertile strain 6.11 (SF). Either polyA ${ }^{+}$, total, or polyA- RNA was used as indicated.
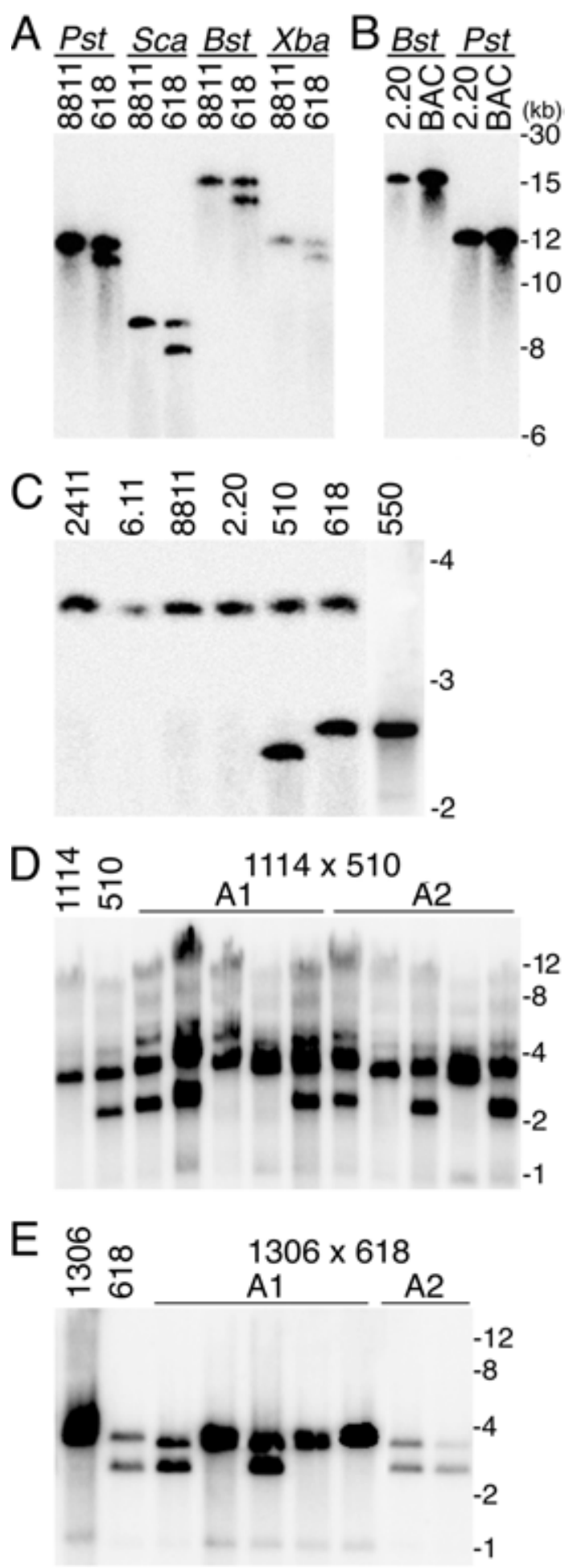

Fig. 2. DNA blot analysis of M81 in Phytophthora infestans. A, and B, DNA was digested with BstXI (Bst), ScaI (Sca), PstI (Pst), or XbaI (Xba), was separated by pulsed-field gel electrophoresis to increase resolution, was blotted, and was hybridized with the 250-nt M81 cDNA (which was later shown to come from the repeat region of M81). DNA was from strains 8811,618 , and 2.20 , or a bacterial artificial chromosome clone from a library of strain 2.20. C, Genomic DNA was digested with EcoRI and $X b a \mathrm{I}$, was separated by conventional electrophoresis, was blotted, and was probed with the 250-nt cDNA. DNA was from A1 strains 2411, 8811, 2.20, A2 strains 510, 618, and 550, and self-fertile strain 6.11. D, and E, DNA from 1114 (A1), 510 (A2), 1306 (A1), 618 (A2), and their progeny (labeled as A1 or A2 mating type) were treated as in C. Size standards in the right margins were determined using a 1-kb DNA ladder or XhoI digest of bacteriophage lambda DNA. 
promoters (Pieterse et al. 1994). There was no evidence for introns throughout most of the transcription unit. However, as discussed below, technical issues precluded testing for introns in the $3^{\prime}$ portion of the gene, which contained about 36 direct repeats of a 90-nt sequence (Fig. 3A, portrayed by vertical hatchmarks).

\section{M81 encodes an elicitor-like protein}

with threonine- and proline-rich repeats.

The predicted protein product of $M 81$ is shown in Figure 3B. Two major domains were found within its 1,607-amino acid sequence. The region from residues 1 to 443 resembles the $P$. sojae elicitor, having $64 \%$ amino acid similarity and $47 \%$ identity (BLAST $E=10^{-99}$ ). An apparent signal peptide was present, as in the P. sojae protein (Sacks et al. 1995). Three predicted Nlinked glycosylation sites in the $P$. sojae protein are not conserved within $M 81$, although three other sites are predicted (Fig. 3B, boxed residues).

The second major domain is a threonine- and proline-rich region of 1,080 amino acids in the C-terminal two-thirds of the protein. Reflecting the presence of the 90-nt repeats in the gene, this contained 31 perfect and 5 diverged direct repeats of TYPPETYAPETTAPATYPPETYSPETTAPS. Within this are three subrepeats of $\mathrm{T}(\mathrm{T} / \mathrm{Y})(\mathrm{P} / \mathrm{A} / \mathrm{S}) \mathrm{P}(\mathrm{E} / \mathrm{A}) \mathrm{TY}(\mathrm{A} / \mathrm{P}) \mathrm{P}(\mathrm{E} / \mathrm{S})$. This region is not in the $P$. sojae protein, which, at 527 amino acids, is much shorter. The $M 81$ repeats are followed by a 40 -amino acid nonreiterated region. Neither region has significant matches to proteins in the GenBank database.
Polymorphic alleles generate the two M81 transcripts.

Several models were evaluated to explain the origin of the two RNA bands observed in A1 $\times$ A2 matings $(8811 \times 618$, Fig. 1; $1306 \times 510$ and $2411 \times 510$, not shown). These included differential transcriptional start or polyadenylation sites, alternative splicing, and heterogeneous alleles. The correct explanation was ultimately shown to be variation in the number of 90-nt repeats between different alleles of $M 81$.

The two transcripts could not be attributed to alternate start or polyadenylation sites, based on studying 5' RACE products or polyA-containing cDNAs. Also, short (approximately 200 nt) probes near the $5^{\prime}$ and $3^{\prime}$ termini of $M 81$ hybridized either to both RNA bands or neither (Fig. 4A, probes 7/9 and 13/14). If multiple termini existed, then at least one probe should have detected only the larger band.

To test if alternate or incomplete splicing caused the two transcripts, RT-PCR was performed (Fig. 4B). This demonstrated the absence of introns in the first 1.4 and last $0.5 \mathrm{~kb}$ of M81, since amplicons from RNA and genomic DNA templates had the same sizes (Fig. 4B, primers 7/12 and 13/14). However, it was impossible to test for introns in the repeated portion of the gene, as the repeats were recalcitrant to PCR. Subcloning the region for RNAse protection or S1 mapping also failed; only rearranged clones were obtained, despite the use of several low- and high-copy plasmids and repeat-tolerant bacteria.

Evidence for heterogeneity in the size of different M81 alleles was obtained by DNA blot analysis. As previously mentioned, DNA from some strains yielded two bands when re-

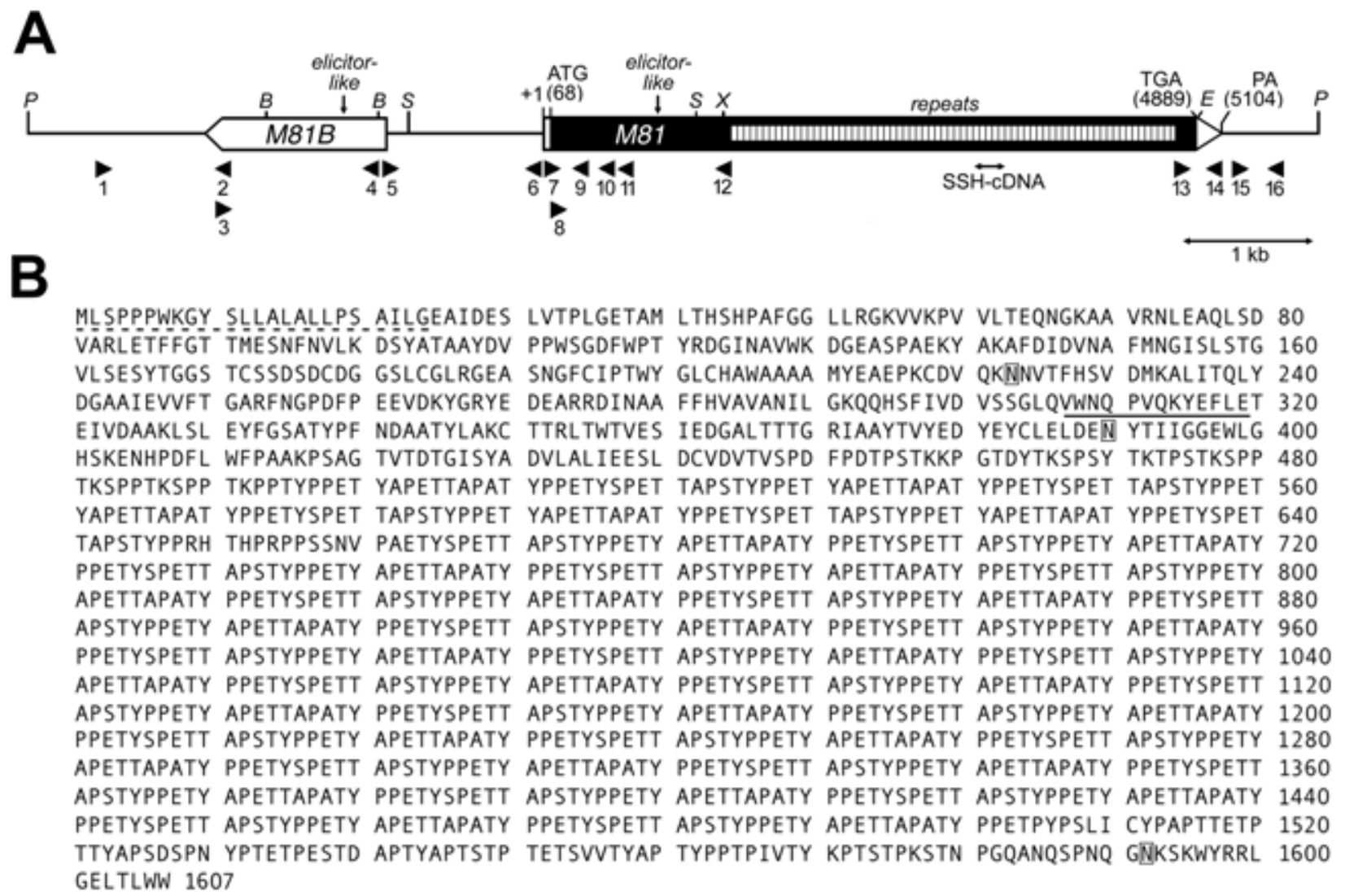

Fig. 3. Structure of $M 81$ gene and protein of Phytophthora infestans. A, Features of a Pst I fragment from a bacterial artificial chromosome clone. Indicated are open reading frames representing the mating-induced $M 81$ gene (black rectangle, oriented to the right) and $M 81 B$ (open rectangle, oriented to the left). For $M 81,68$ - and 216-nt $5^{\prime}$ and $3^{\prime}$ untranslated regions, start codon, and polyadenylation site are portrayed by an open rectangle, open triangle, ATG, and PA, respectively. The hatched region within $M 81$ represents the repeated domain. The elicitor-like (Pep-13) regions are indicated. Below the horizontal line are arrows representing primers 1 to 16 and the approximate position of the 250-nt cDNA (SSH-cDNA). Restriction sites are: $B, B s t$ XI; $E$, EcoRI; P, PstI; S, ScaI; and X, XbaI. B, Predicted M81 protein. A signal peptide predicted by SignalP is represented by the dashed underline, and glycosylation sites predicted by NetNGlyc are boxed. The Pep-13 motif is marked by the solid underline. 
stricted with enzymes not cutting within M81 (Fig. 2A). This was found to result from interallelic variation in the number of repeats, by blot analysis using enzymes that cut $5^{\prime}$ and $3^{\prime}$ to the repeat region of $M 81$. Figure $2 \mathrm{C}$ shows a probe from the repeat region hybridized to DNA digested with EcoRI plus XbaI, which both cut within M81. Strains of $P$. infestans either had a 3.5-kb band (i.e., 8811), a band of about $2.5 \mathrm{~kb}$ (550), or both $(510,618)$. This explains why $5.1-$ and $4.1-\mathrm{kb}$ RNAs were in the $8811 \times 618$ matings, as large and small alleles were present. It also indicates why self-fertile strain 6.11 only made the 5.1-kb RNA, since it was a homozygote of the larger allele.

Curiously, the only isolates that contained small M81 alleles were of the A2 mating type $(510,550,618)$. To test if this was evidence of linkage with mating type, the segregation of M81 was scored in $1114 \times 510$ and $1306 \times 618$ crosses. Mating type and $M 81$ were unlinked, as nine recombinants were detected in

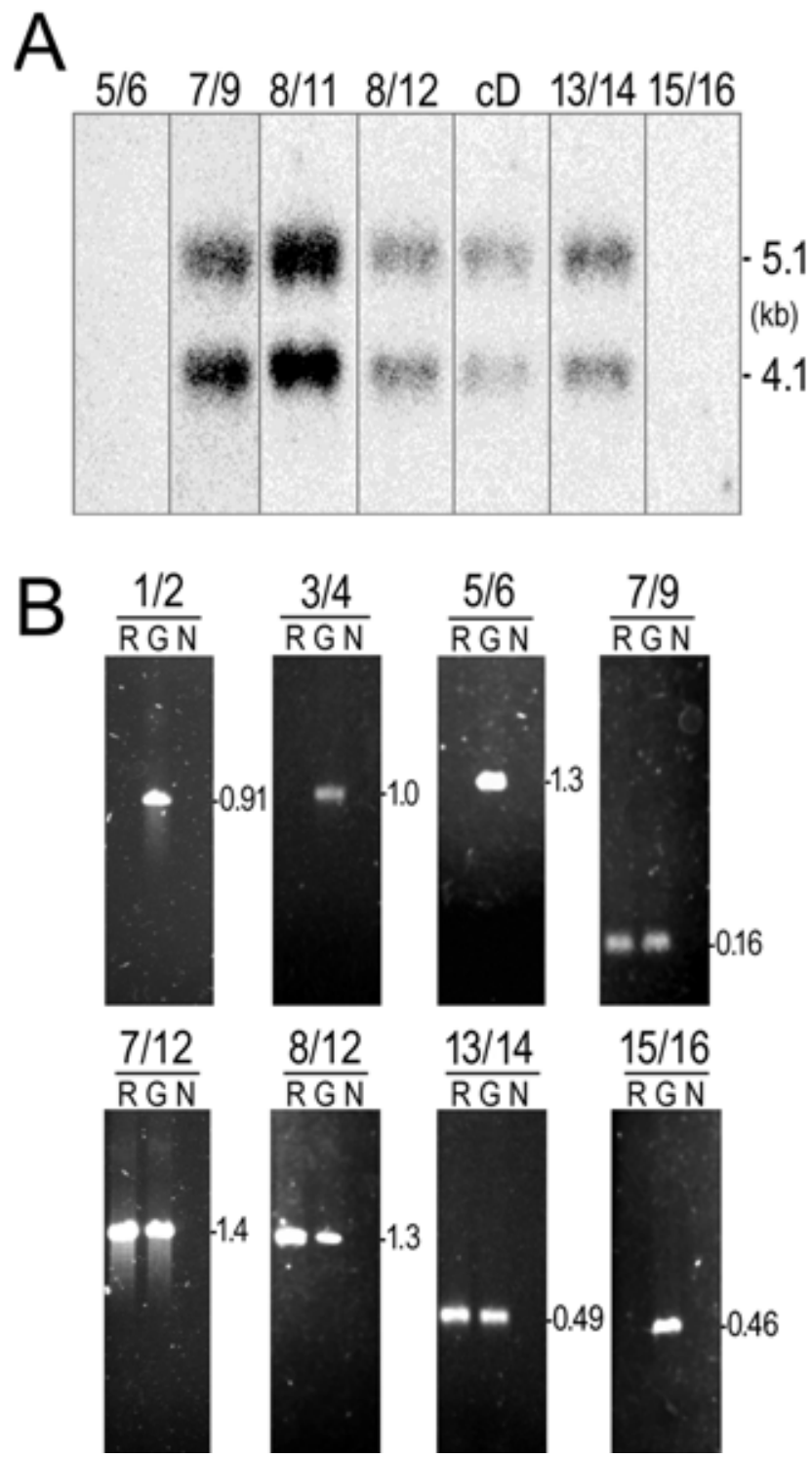

Fig. 4. Transcript mapping of M81 in Phytophthora infestans. A, RNA blot analysis against polyA ${ }^{+}$RNA from a 5 -day $8811 \times 618$ mating. The label above each panel represents the hybridization probe. These were amplified by polymerase chain reaction (PCR), using the indicated primers or the 250-nt M81 cDNA (cD). B, Reverse transcription-PCR performed using RNA as template (R) or no template $(\mathrm{N})$, and PCR performed against genomic DNA from 8811 and $2.20(\mathrm{G})$. The numbers above each panel (1/2 to 15/16) represent the primers employed. Samples were electrophoresed and sized using a DNA ladder.
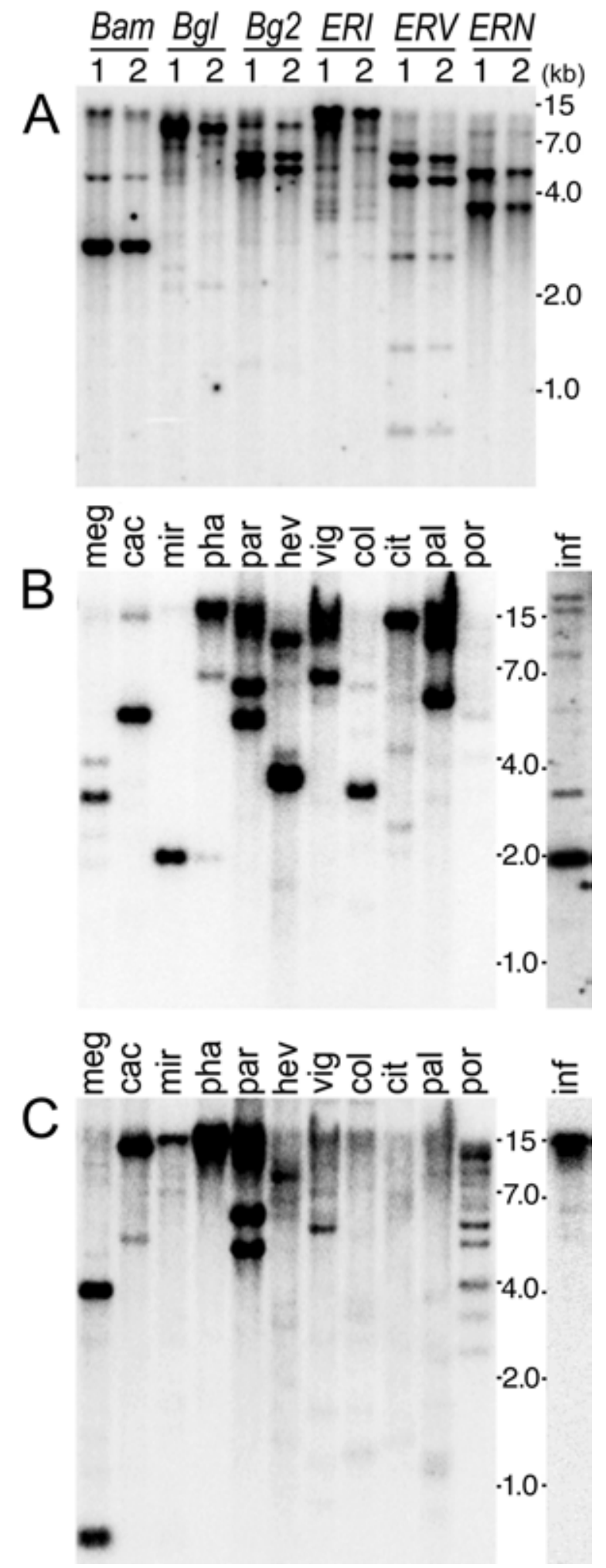

Fig. 5. DNA blot analysis of the M81 family in Phytophthora infestans. A, DNA from P. infestans isolates 1114 (1) and 510 (2) hybridized at low stringency with a probe representing the elicitor-like region of $M 81$ amplified using primers 7 and 12. Digests employed BamHI (Bam), BglI $(B g l), B g l \mathrm{II}(B g 2), E c o$ RI $(E R I), E c o$ RV $(E R V)$, or EcoNI (ERN). B, Lowstringency hybridizations of elicitor-region probe against ScaI-cleaved DNA from $P$. megasperma (meg), P. cactorum (cac), P. mirabilis (mir), $P$. phaseoli (pha), P. parasitica (par), P. heveae (hev), P. vignae (vig), $P$. colocasiae (col), P. citricola (cit), P. palmivora (pal), P. porri (por), and $P$. infestans (inf). C, Same blot as B probed with the 250-nt M81 cDNA from the repeat region. Size standards are from a DNA ladder. 
17 progeny (Fig. 2D, E). Since the lower band segregates, these data also help indicate that it is an alternate allele and not an extra copy of M81. Also, the average ratio of the $3.5-$ and $2.5-\mathrm{kb}$ hybridization signals was about $1: 1$, as expected for alleles. This ratio varied in some progeny, consistent with nondisjunction events, which are common in Phytophthora spp. (Förster and Coffey 1990).
M81 relatives

in Phytophthora have elicitor or repeat domains, or both.

Low-stringency blot analysis of $P$. infestans DNA using the 250-nt cDNA as a probe did not reveal evidence for related sequences in the genome (Fig. 2A). However, different results were obtained using probes from other regions of $M 81$. Probes from the elicitor-like domain of the protein detected several

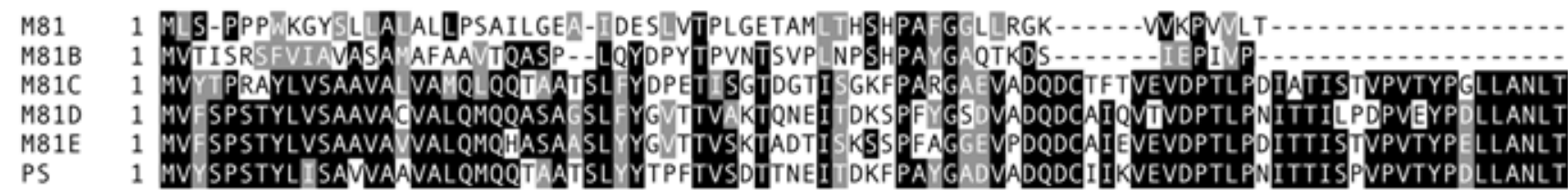

PS

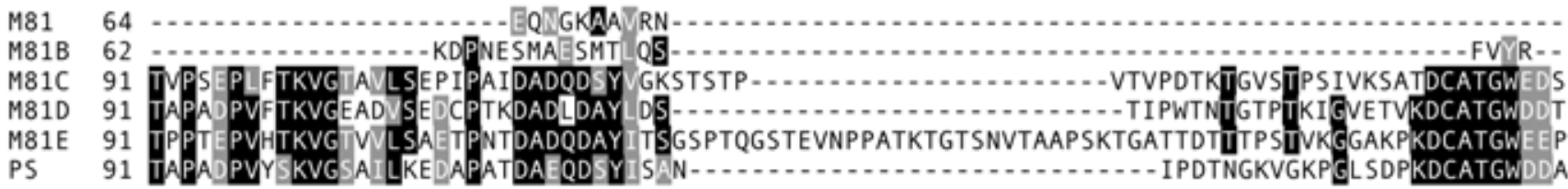

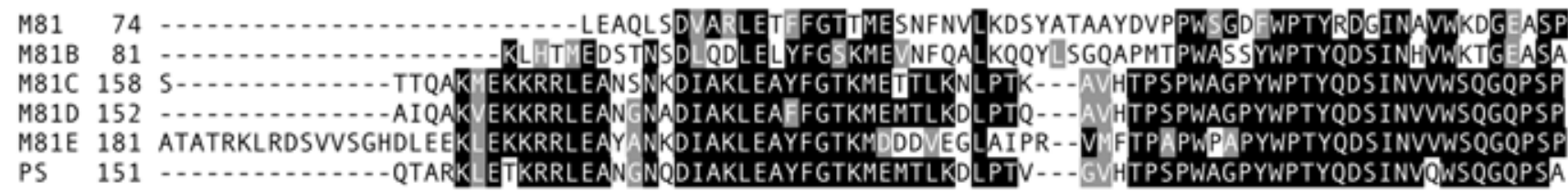

M81 137 AEKYAKAFDIDVNAFMNG SLSTGVLSESYTGGSTCSSDSDCDG - -GSLCGLRGEASNGECIPTWYGLCHAWAAAAVYEAEPKCDVQKN M81B 149 SEKYAKAYAMWVTDFKDKIS SARSGIDSRKRR - - PVCTISSDCTSRKDGSVCAKRDGMS SGYCIPAWLGICHAWAPAAILEPEPDCDNTKN M81C 231 AEKYAKAFGKDVTAFMD VSKKNGIDSHSGR--KKCTSKNDCASLTDGSECAIRPGKSSGYCIPTWFGICHAWAPAAILEAEPNCPVT Y M81D 197 AEKYAKAFGKDVTAFMDAVSKKNGIDSHSGR - KKCTSKNDCASLTDGSECAIRP GKSSGYCIPTWFGICHAWAPAAILEAEPNCPVT YN M81E 269 AEKYAKAFG DVKEFMDKVSKDNGVDSGKR - TKCSSDNDCASRTDGSKCAIRDGKSSGYCIPAWFGICHAWAPAAILEAEPTCPVTYN PS 223 AEKYAKAFGKDVKTFMD VSK NGIDSOSGR--KKC SDDDCSTLLDGSSCSIRTGKTSGYCIPTWFGICHAWSPAAILETEPKCPVKHN

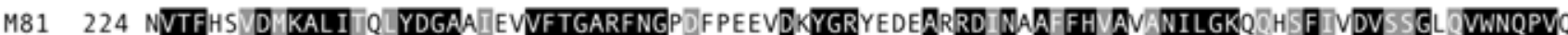
M81B 237 GVTFHVMDIKGLLTS YOGAS IKTVFTGARFNGSDSPANKDQ YGRFTDASRRDLGAGFFHIAITNI MAKHNQPFWDVTSGAEVWNQPVR M81C 319 GVTFQPMD KAL IS SVYDGARVATVFTGARFNGG D - STDEYGRH SNAYRDL NPAYFHIANSNILGKLNSTYVADVTAGAEVWNQPVR M81D 312 GVTFQPMD KAL IS SVYDGARVATAFTGARFNGG D - STDEYGRHSSNAYRDLNPAYFHIANSNILGKLNSTYVADVTAGAEVWNQPVR M81E 357 GVTFQPLDIKGLISNVYDGASVATVFTGAR NGGD - GADEYGRHTNAAYRDLNPAYFHIAS S IL GKLNATFVADVDAAAEVWNQPVR PS 311 GVTFQPMD KALVSLVYDGARVQTVFTGARFNGGTD- - ITTDEYGRH NNAYRDLNPAYFHIASANILGKLNSTFVADVTAGAEVWNQPVR

M81 314 KȲEFLETE IVDAAKLSLEYFGSATYPFNDAATYIAKCTIRLTWTVESIEDG LITIGRIA M81B 327 SFKVQNMDLVDTHVASMRYFG PSYPFSDKMVHLAYVKISFSWVVES YKDG PLVYSVQID M81C 407 GFKVYEQTKM SLKKAAQTFYGLQKYPWINSAAKSIVYVKSRL SWI ETYTDGGLVSSGAIN M81D 400 GFKVYEQTKMSLKKAAQTFYGLQKYPWWAAAKS IVYVKSRLSWI ETYTDGGLVSSGAI M81E 445 GFKVYEQTAM SLEEAAQTFYGLEEYPWSAAAKSIVYVKSRL SWI ETYTDGGLVSSGE DD PS 399 GFKVYEQTEMTLEEGAQTFYGLEAYPWINAAAKS VYVKSRLSWI ETYTDGGLVSSGOID

M81 374 AYTVYEDYEYCLELDENYTIIGGEWLGHSKENHPDFLWFPAAKP SAGTVTDTGI M81B 387 SYTTFKDYEYLRSWMPTTTSSEANGLMRI-T--PIFCGFRRPNPTQLPSPALV* M81C 467 QYTTGQYYHYLLELDSAGE I IGGEWVYGSDD DHPDFLWLPKAKPAANSVTSIGL M81D 460 QYTTGQYYQYLLELDSAGE I IGGEWVYGSD D DHPDFLWLPKAKPAANIVTSIGL M81E 505 RYTTGKYYYYLLELDDAGE I IGGEWVYSSDSDHPDFLWFAKSKPAADMVTSIGL PS 519 KFTTGQYYYYLLELDDAGEI IGGEWVYGSD DDHPDFLWLPKAKPAANIVTS VGL

M81 428 SYADVLALIEESLIDCVDVTVSPDFPDTPSTKKPGTDYTKSPSYTKTPSTKSPPT M81C 521 SYADVSMLLOKS LSC* M810 514 SYADVSMLLQKS SSC*

M81E 559 SYADVSMLLKKS ACSDSASASGSAGSSSASASASAATSTSGSVGASTSGSATS PS 563 SYADVSMLLKKSAACTA*

M81 477 KSPPTKSPPTKPP (ca. 34 "REPEATS") APTTETPTTYAPSDSPNYPTET M81E 613 SASTSTGSTTDVPFTSSTASNGGSAATEVPATEAPATEAPATETPVATTQNGGA M81 1536 PESTDAPTYAPTSTPTETSVVTYAPTYPPTPIVYKPTSTPKSTNPGQANQSPNQ M81E 667 TTAPASTTAPPAATTATPSNNGGNQGGNNGGNN NQNDNHYQQYQQQQQQQQQQF

M81 1589 GNKSKWYRRLGELTLWW*

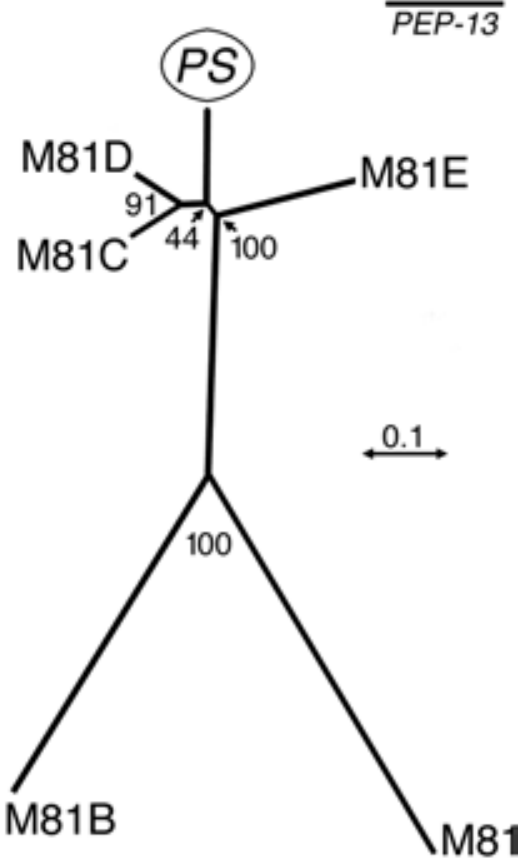
M81E 721 ENSDHPRQWYQSFFHWW*

Fig. 6. Relationships between elicitor-like proteins from Phytophthora infestans (M81 to M81E) and P. sojae (PS). Sequences are shown from start codon to terminator (*), except for the reiterated region between amino acids 486 and 1514 of M81, which is abbreviated as " 34 repeats." The Pep-13 region is underlined. Blocks of identical or similar amino acids are marked by black or gray backgrounds, respectively. Also shown is a phylogram depicting the consensus neighbor-joining tree, with numbers at nodes indicating their percent occurrence in 500 bootstrap replicates and the scale representing 0.1 PAM units. 
bands (Fig. 5A). This suggested that a gene family existed in which most members lacked the repeat domain, like the $P$. sojae elicitor.

Genes containing the elicitor, repeat, or both domains were detected in other members of the genus (Fig. 5B and C). In species such as $P$. cactorum, $P$. phaseoli, and $P$. parasitica, elicitor and repeat probes hybridized to overlapping patterns suggestive of a $M 81$ homologue. In species like $P$. citricola, the elicitor but not the repeat probe detected a clear signal, while the opposite was true with $P$. porri.

The structures of the additional members of the $M 81$ family in $P$. infestans were discerned by sequencing genomic and cDNA clones. This identified $M 81 B$, which was physically linked to $M 81$ (Fig. 3A), plus $M 81 C$, M81D, and M81E. Full-length cDNAs were identified for the latter three genes; however, no cDNA clones corresponding to $M 81 B$ were detected. $M 81 B$ may be an untranscribed pseudogene, as no signal was obtained in RNA blots or by RT-PCR against RNA from different stages of asexual or sexual development (Fig. 4B, primers 3 and 4).

Compared with the 1,607-amino acid protein predicted for $M 81$, the other genes encoded proteins closer in size to the $P$. sojae elicitor. These ranged from 436 to 737 amino acids and lacked the repeat region (Fig. 6). The $M 81 C, M 81 D$, and $M 81 E$ proteins were more related to each other (68 to $83 \%$ identity) and the $P$. sojae protein (63 to $71 \%$ identity) than to $M 81$ or $M 81 B$ (47 to $48 \%$ identity), although the latter two were not very similar (44\% identity). Amino acid similarity was higher in the region aligned with the C-terminal two-thirds of the $P$. sojae protein, which is believed to confer transglutaminase activity (Brunner et al. 2002). The 13-amino acid region conferring elicitor activity in $P$. sojae (Pep-13) (Nuernberger et al. 1994) was $100 \%$ conserved in $M 81 C, M 81 D$, and $M 81 E$ and was altered at three positions in $M 81 B$ and six in M81. Signal peptides were predicted for all proteins.

The $M 81$ and $M 81 E$ proteins shared several features not found in other family members. Both contained reiterated patterns of uncharged amino acids near their C-termini, albeit more extensively in M81. Their C-termini also contained ditryptophan tails and were enriched for glutamines. The latter was manifested in $M 81 E$ as a stretch of 10 glutamines, a feature associated with protein-protein interactions. This was derived from $10 \mathrm{CAG}$ codons, suggesting that expansions of trinucleotide repeats occur in Phytophthora spp. as in animals (Bao et al. 1996).

\section{The mating-induced $M 81$ gene lacks elicitor activity.}

The $M 81 C, M 81 D$, and $M 81 E$ proteins perfectly match the Pep-13 region of the $P$. sojae protein, which induces some defense responses in parsley and potato (Brunner et al. 2002). It follows that these $P$. infestans proteins also have elicitor activity, assuming that they fold into a conformation similar to the $P$. sojae protein. It is less obvious that the $M 81$ protein would be an elicitor, since only 7 of the 13 amino acids are conserved. To address this, Pep-13 and a 13-mer from the corresponding portion of $M 81$ were tested for the ability to induce in parsley the accumulation of coumarins, one component of the defense response. While coumarins accumulated in a dose-dependent manner in response to Pep-13, the $M 81$ peptide exhibited no activity (Fig. 7). The $M 81$ peptide also failed to induce visible necrosis in parsley, soybean, potato, or tomato leaves, although it should be noted that Pep-13 has not been reported to induce this response in parsley. A $M 81 B$-derived peptide was not tested, since that gene is apparently not expressed.

\section{Family members show diverse patterns of expression.}

Of the five genes from $P$. infestans, only $M 81$ was induced during mating (Fig. 8). Timecourses of $8811 \times 618$ interactions revealed that $M 81$ transcripts peaked at an intermediate stage of sexual development, seven days after matings were initiated (Fig. 8A, lane 7D). Young gametangia (antheridia and oogonia) and immature oospores were the major sexual structures at this time. M81 transcripts were at very low levels at four days, when hyphal swellings representing gametangial primordia predominated (Fig. 8A, lane 4D), and after 11 days, when maturing oospores were the principal sexual structures (Fig. 8A, lanes $11 \mathrm{D}$ and 15D). An enrichment of the $M 81$ signal was observed in purified oospores (Fig. 8A, lane OO), although accurate quantitation was impaired by RNA degradation, which is a typical feature of oospore preparations. Strong expression was also observed in a self-fertile strain $\left(7 \mathrm{D}-\mathrm{SFOO}^{+}\right)$. Transcripts were not detected in cultures of A1 or A2 strains grown separately (7D-A1 and 7D-A2) or in a self-fertile strain grown under submerged conditions that repress oosporogenesis $\left(7 \mathrm{D}-\mathrm{SFOO}^{-}\right)$.

M81 transcripts were not detected during developmental stages other than mating (Fig. 8B). Also, no expression was detected in response to various stresses reported to stimulate sexual development in single-mating-type cultures of Phytophthora spp. (Groves and Ristaino 2000; Leal et al. 1967). These included nitrogen starvation (A1-N; Fig. 8B), carbon starvation, and fungicide treatment (data not shown).

$M 81 C$ and $M 81 D$ were expressed in a zoospore-specific pattern, in contrast to M81 (Fig. 8B). Since several lanes in this RNA blot were underloaded, quantitations relative to elongation factor- 1 mRNA are shown at the base of the figure. Transcripts were first detected in cleaving sporangia (sporangia placed in cool water to initiate zoosporogenesis) (Fig. 8B, lane A1CL), reached their highest abundance in zoospores (Fig. 8B, lane A1Z), and fell in zoospore cysts (Fig. 8B, lane A1ZC) and germinated cysts (Fig. 8B, lane A1GC). No expression was detected in hyphae (Fig. 8B, lane A1HY) or infected tomato (Fig. $8 \mathrm{~B}$, lane A1P).

In contrast to the other genes, $M 81 E$ displayed hyphal-specific expression (Fig. 8B). Its transcript was most abundant in hyphae, germinated cysts, infected tomato, and mating cultures (which mostly contain hyphae). The $M 81 E$ signal was greatly reduced in asexual sporangia and did not reappear until after zoospores released from the sporangia had encysted and germinated to form new hyphae.

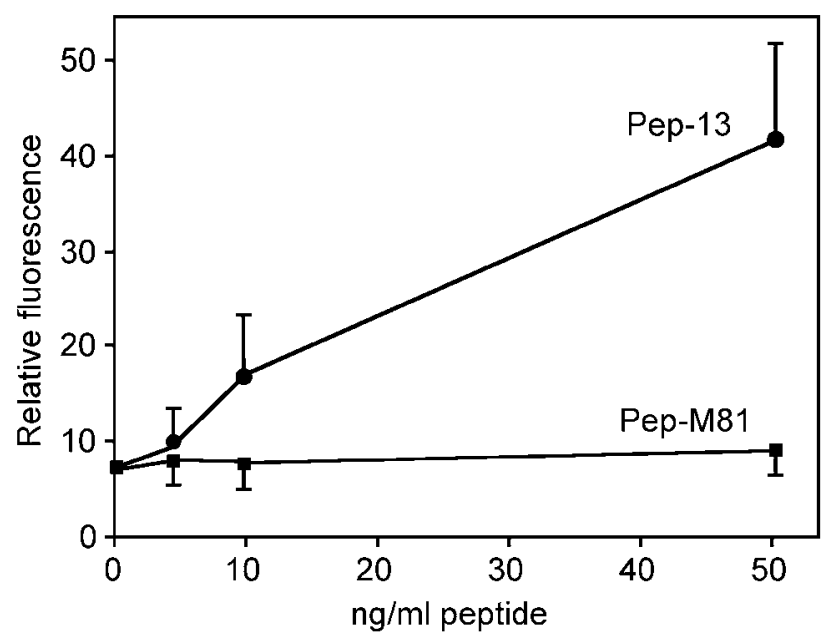

Fig. 7. Response of parsley to oligopeptides from $M 81$ family. Leaf disks were infiltrated with 13-mer peptides from the region corresponding to the Pep-13 elicitor of the Phytophthora sojae protein (identical to that of $M 81 C, M 81 D$, and $M 81 E$ ) or $M 81$. After $12 \mathrm{~h}$, coumarin accumulation was determined by measuring fluorescence. Values are the average of six disks \pm standard deviation. 


\section{DISCUSSION}

This paper has described a family of diverse elicitor-like proteins that is widely distributed throughout Phytophthora spp. That its relative from $P$. sojae elicits defense reactions in plants has been known for many years (Parker et al. 1988), but only recently were clues to its function in the normal biology of Phytophthora spp. obtained. Knowledge that this family encoded transglutaminases was the fortuitous result of a screen for protein cross-linking enzymes for the food industry (Bech

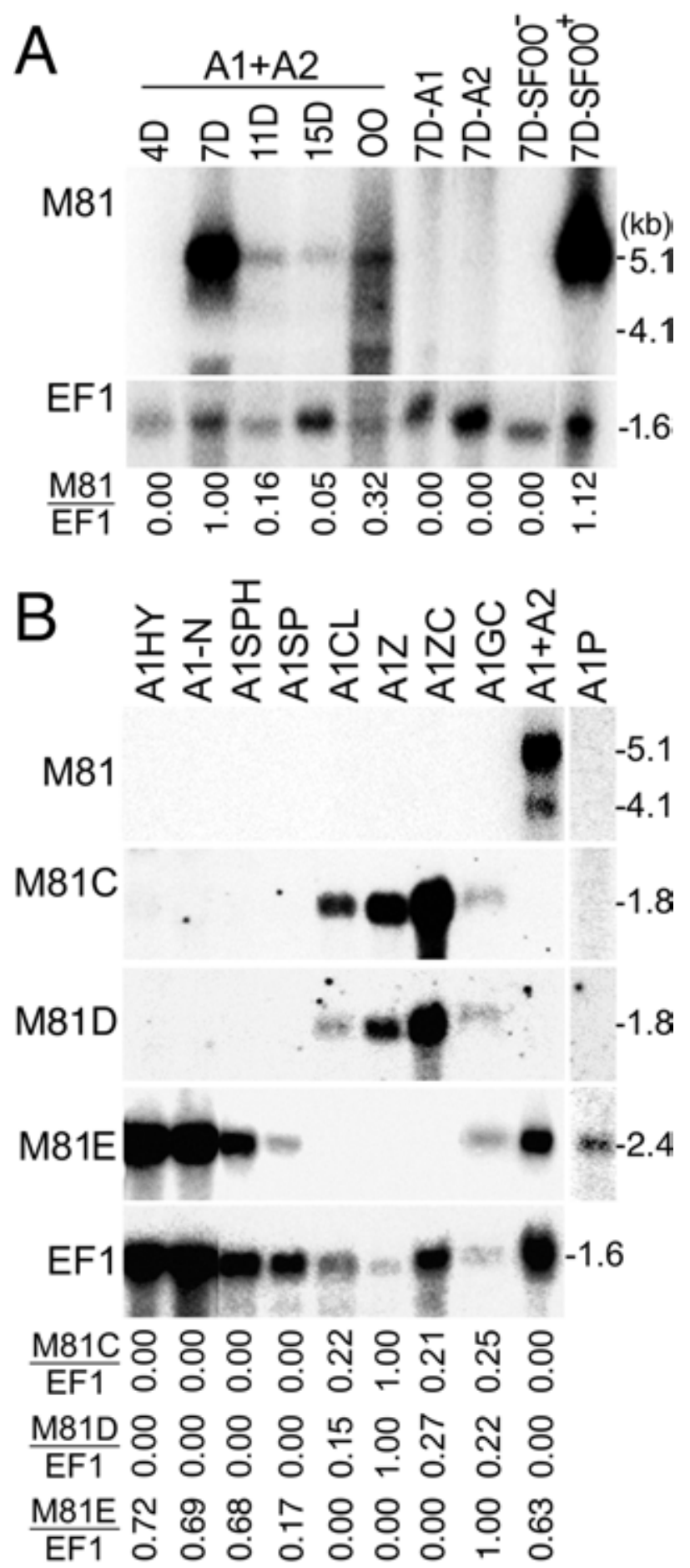

Fig. 8. Expression of $M 81$ family members in Phytophthora infestans. Gene-specific probes for $M 81, M 81 C, M 81 D, M 81 E$, or elongation factor-1 (EF1), as indicated in the left margin, were hybridized to total RNA at high stringency. A, Blot of RNA from the mating interaction zones of 4-, 7-, 11-, and 15day $8811 \times 618$ cultures $(4 \mathrm{D}, 7 \mathrm{D}, 11 \mathrm{D}$, and 15D); oospores purified from hyphae in the 15-day culture (OO); 7-day membrane cultures of 8811 (7D-A1) and 618 (7D-A2); a 7-day culture of submerged 6.11 hyphae that lacked oospores (7D-SFOO ${ }^{-}$); and a 7-day membrane culture of 6.11 that contained oospores (7D-SFOO ${ }^{+}$). B, Blot of RNA from nonsporulating hyphae of A1 isolate (A1HY), nitrogen-starved hyphae (A1-N), 10-day hyphae containing asexual sporangia (A1SPH), purified sporangia (A1SP), cleaving sporangia (A1CL), motile zoospores (A1Z), zoospores 5 min after inducing encystment (A1ZC), cysts germinated in water for $8 \mathrm{~h}$ (A1GC), and RNA from a 7-day mating culture (A1+A2). The panel on the right represents a separate blot containing RNA from 5-day infected tomato leaflets (A1P). A probe for $M 81 B$ was also tested but showed no hybridization. Shown beneath the blots are ratios of transcript signals normalized to EF1, adjusted such that the maximum for each gene equals 1.0. These were calculated by phosphorimager analysis, using either the exposures shown or others selected to lie within the linear range of response of the phosphorimager. 
et al. 2002). Additional information useful for discerning the biological role of the genes is provided by our data on their structure and stage-specific transcription in $P$. infestans. The expression pattern of the $P$. sojae gene had not been determined (Sacks et al. 1995).

Transglutaminases (EC 2.3.2.13) catalyze calcium-dependent acyltransferase reactions between a $\gamma$-carboxyamide group of glutamine and the $\varepsilon$-amino group of lysine or other primary amines, giving rise to intramolecular or intermolecular peptide chain bridges. This activity is widely distributed in archaea, bacteria, and eukaryotes, although the Phytophthora proteins are structurally unrelated to other transglutaminases (Brunner et al. 2002; Makarova et al. 1999). The portion of the $P$. sojae protein needed for enzyme activity overlaps with the Pep-13 region; based on identity here and elsewhere throughout the protein, the products of $M 81 C, M 81 D$, and $M 81 E$ are also predicted to have this enzymatic activity. This is less obvious for the most diverged member of the family, M81. Attempts to express the $M 81$ protein for enzyme assays have so far been unsuccessful.

Besides their predicted transglutaminase function, the $P$. infestans proteins share characteristics consistent with being secreted or a component of the cell wall. All have apparent signal peptides, like the $P$. sojae protein. Except for the potentially nonexpressed $M 81 B$ protein, all have acidic pIs (3.9 to 5.5) and sites for O-glycosylation; both traits are common in extracellular proteins (Spiro 2002). Also, the M81 protein contains an extensive proline- and threonine-rich domain, while the $M 81 E$ protein has serine- and alanine-rich tracts. Such features are typical of proteins that contribute to the structure of cell walls or adhesion in the extracellular matrix (Filpula et al. 1990; Fosnaugh and Loomis 1989; Görnhardt et al. 2000; Keller and Lamb 1989; Smythe et al. 1990).

The above characteristics imply that the normal role of the M81 family of proteins in the biology of Phytophthora spp. is to strengthen its cell walls or enhance adhesion. The latter function may include interactions between different Phytophthora structures (as during mating) or with plants (during penetration or haustoria formation). The cell walls of hyphae, zoospores, and sexual structures of Phytophthora spp. are biochemically and structurally distinct (Bartnicki-Garcia and Wang 1983; Hemmes and Bartnicki-Garcia 1975). Each may require functionally distinct enzymatic activities conferred by the M81 family, explaining the diverse structures and transcription patterns of the genes. Our hybridization studies using probes from the elicitor-like and threonine- and proline-rich repeat regions of $M 81$ indicate that structural diversity within the family also exists in other members of the genus, and it is predicted that their genes also exhibit stage-specific expression. Transglutaminases are also developmentally regulated in other species, as in sea urchin, in which the protein helps hardens egg fertilization membranes (Battaglia and Shapiro 1988), in Chlamydomonas reinhardtii, during wall formation during mating (Waffenschmidt et al. 1999), and in Physarum polycephalum, during the generation of thick-walled spherules (Klein et al. 1992).

From the perspective of the plant, the role of the transglutaminases in the growth and development of Phytophthora spp. is secondary to their expression in a time and place suited to exploitation as a signal of pathogen invasion. Whether this involves crosslinking a plant receptor or other mechanisms is unclear, although the receptor in parsley is a membrane protein (Nennstiel et al. 1998). Candidates for interaction with the receptor are $M 81 C$ and $M 81 D$, which are expressed in zoospores and cysts, and hyphal-specific gene $M 81 E$.

Although the number of M81-like genes reported here resembles the number of bands in DNA blots (Fig. 5A), addi- tional family members may exist that interact with the plant. A search of public databases containing $P$. infestans and $P$. sojae expressed sequence tags (ESTs) mainly identified clones containing Pep-13 (VWNQPVRGFKVYE) but also a $P$. infestans EST with VWNHPVDGFTVHE and an EST from $P$. sojae containing VWNQPVRSFVVRN. Whether this divergence in sequence impacts host species or cultivar-specificity is a matter of conjecture. However, isolates of $P$. infestans vary in their induction of defense reactions in different host species (Oyarzun et al. 1998), and the $M 81$ family represents candidates for mediators of such interactions.

When considering the elicitor activities of the M81 family and orthologues, it is important to note that their importance in plant interactions is unproved. Determining their contribution to nonhost resistance, as in $P$. sojae or $P$. infestans interactions with parsley, or to the necrosis typical of compatible infections of potato by $P$. infestans (Shimony and Friend 1975) requires silencing the M81 family or its plant receptor. Gene silencing in oomycetes is not routine, and attempts to silence members of the transglutaminase family have so far failed (Brunner et al. 2002; H. Judelson, unpublished data). Moreover, most members of the family would likely need to be inactivated to change the interaction phenotype. While the existence of a family imposes technical obstacles to such functional studies, it also helps explain the evolutionary persistence of the M81 genes. Altering the family may enhance the ability of Phytophthora spp. to evade plant defenses, but this potential advantage may be insufficient to overcome the dual hurdles of mutating multiple genes and of surviving without their transglutaminase functions.

\section{MATERIALS AND METHODS}

\section{Strains and culture conditions.}

A1 strains of $P$. infestans used were Ca65 (U.S.A.), 1114 (Netherlands), 1306 (U.S.A.), 8811 (U.K.), 2.20 ( $\mathrm{F}_{1}$ of 8811 and E13a), and $2411\left(\mathrm{~F}_{1}\right.$ of $\mathrm{Ca} 65$ and $\left.93 \mathrm{H} 3\right)$. A2 strains were 510, 550, and 618 (Mexico), and 93H3 (U.S.A.). Strain 6.11 is a self-fertile heterokaryon derived from a cross between 2411 and 510, which contains a mixture of A1 and A2 nuclei (Fabritius et al. 2002). Other species are described elsewhere (Judelson and Tooley 2000).

$P$. infestans was routinely cultured at $18^{\circ} \mathrm{C}$ in rye A agar (Caten and Jinks 1968). Cultures for DNA extractions used clarified rye A broth. RNA from nonmating and mating hyphae was generally isolated from cultures grown on polycarbonate membranes (Fabritius et al. 2002). Mating cultures contained parallel strips of A1 and A2 inoculum, placed $2.5 \mathrm{~cm}$ apart. Oospores were purified from such cultures by homogenizing the mycelial mat for $30 \mathrm{~s}$, followed by filtration through 100 $\mu \mathrm{m}$ mesh and centrifugation at $1500 \times g$ for $15 \mathrm{~min}$. Asexual sporangia, cleaving sporangia, zoospores, encysted zoospores, germinated zoospore cysts, and nitrogen and carbon-starved cultures were obtained as described (Judelson and Roberts 2002). Metalaxyl treatments $(2.5 \mu \mathrm{g} / \mathrm{ml})$ employed hyphae in rye broth. Infected tomato samples were obtained by placing $10 \mu \mathrm{l}$ of a zoospore suspension $\left(10^{5} / \mathrm{ml}\right)$ on detached leaflets of 6-week-old plants (cv. New Yorker), which were incubated for 6 days at $16^{\circ} \mathrm{C}$ at high humidity and then were harvested.

\section{Nucleic acid blotting.}

DNA and RNA were extracted as described (Fabritius et al. 2002). PolyA ${ }^{+}$RNA was purified using paramagnetic oligo-dT beads, and polyA ${ }^{-}$RNA was recovered from the unbound material by ethanol precipitation. Blots were prepared from agarose gels and hybridized as described (Judelson and Roberts 2002). The DNA gels either involved conventional electropho- 
resis parameters or pulsed-field conditions using a PPI-200 controller (MJ Research, Waltham, MA, U.S.A.) set to program B. Probes for blots were a 250-nt M81 cDNA obtained by suppressive subtraction hybridization PCR (Fabritius et al. 2002) or PCR-amplified portions of the genes. High stringency washes were in $0.1 \times \mathrm{SSPE}(1 \times \mathrm{SSPE}$ is $0.18 \mathrm{M} \mathrm{NaCl}, 10 \mathrm{mM}$ $\mathrm{NaH}_{2} \mathrm{PO}_{4}, 1 \mathrm{mM}$ EDTA), $0.2 \%$ sodium pyrophosphate, and $0.2 \%$ sodium dodecyl sulfate (SDS) at $65^{\circ} \mathrm{C}$ for DNA blots and $70^{\circ} \mathrm{C}$ for RNA blots. Low-stringency washes involved $2 \times$ SSPE, $0.2 \%$ sodium pyrophosphate, and $0.2 \%$ SDS at $55^{\circ} \mathrm{C}$. Signals were detected using a phosphorimager and quantitated using Quantity One for Macintosh (Biorad, Richmond, CA, U.S.A.). Band sizes were determined using RNA ladders from Promega (Madison, WI, U.S.A.) or DNA ladders from Invitrogen (Carlsbad, CA, U.S.A.).

\section{Sequence analysis of genomic and cDNA clones.}

Sequences were obtained from genomic and cDNA clones as described below and above. The BAC containing M81 and $M 81 B$ was sequenced by primer walking and a transposon insertion strategy using the EZ::TN $<$ DHFR $>$ Tnp Transposome kit (Epicentre Technologies, Madison, WI, U.S.A.). Other clones were sequenced by primer walking. Data was assembled using Seqman for Macintosh (DNASTAR, Madison, WI, U.S.A.) and were analyzed for signal peptides or $\mathrm{N}$ and $\mathrm{O}$ linked glycosylation sites using, respectively, SignalP (Nielsen et al. 1997) or NetNGlyc and NetOGlyc (available on-line from Center for Biological Sequence Analysis, Technical University of Denmark). Protein alignments were performed using AlignX for Macintosh (Informax, Frederick, MD, U.S.A.), were formatted for publication using BOXSHADE (available on-line from the Swiss Institute of Bioinformatics), and were exported to the Phylip suite of programs for tree-building (Felsenstein 1989). The latter involved generating 500 bootstrap replicates using Seqboot, a distance matrix using ProtDist (PAM option) and consensus trees using Neighbor followed by Consense.

\section{Transcript mapping.}

The $3^{\prime}$ end of transcription units were mapped by sequencing polyA-containing clones from cDNA libraries made in pSPORT1 (Invitrogen). Transcription start sites were determined by sequencing full-length cDNAs or 5' RACE products, and RT-PCR was used to test for introns using DNAse-treated RNA. Amplification products were cloned into pGEMT-Easy (Promega) prior to sequencing. These experiments used the $5^{\prime}$ RACE and One Step RT-PCR kits from Invitrogen, RNA from mating and hyphal cultures, controls performed without reverse transcriptase, and M81-specific primers. Sites of these primers are illustrated in Figure 3A, and their precise locations on the M81-containing PstI fragment (GenBank accession number AY237402) are as follows: Primer 1 , nt 811 to $828 ; 2,1,718$ to 1,$701 ; 3,1,710$ to 1,$727 ; 4,2,721$ to 2,$703 ; 5,2,863$ to 2,$880 ; 6$, 4,125 to 4,$102 ; 7,4,140$ to 4,$158 ; 8,4,160$ to 4,$180 ; 9,4,301$ to 4,$283 ; 10,4,570$ to 4,$550 ; 11,4,617$ to 4,$602 ; 12,5,507$ to 5,$483 ; 13,8,702$ to 8,$719 ; 14,9,187$ to 9,$169 ; 15,9,214$ to 9,232 ; and $16,9,667$ to 9,651 .

\section{Elicitor assays.}

Oligopeptides corresponding to Pep-13 and the homologous region of M81 (Brunner et al. 2002) were purified by high-performance liquid chromatography, desalted, verified by MALDI-TOF, and tested for their ability to induce coumarin accumulation in parsley (Petroselinium crispum var. neapolitanum), as described (Parker et al. 1988). Briefly, this involved excising from leaves $1-\mathrm{cm}$ disks that were infiltrated using a syringe with aqueous solutions of each peptide, were floated

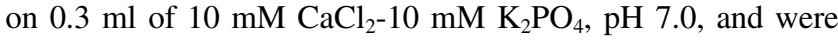
incubated for $12 \mathrm{~h}$ in the dark. The fluorescence of the underlying fluids was measured using a Biorad fluorometer $(340 \mathrm{~nm}$ excitation, $460 \mathrm{~nm}$ emission). Infiltrated potato, tomato, and soybean leaf tissue was also scored visually for necrosis or phenolic accumulation.

\section{ACKNOWLEDGMENTS}

This work was supported by grants from the United States Department of Agriculture and the National Science Foundation. We thank C. Cvitanich and K. S. Kim for providing experimental materials, and, along with F. Brunner and T. Nürnberger, for helpful discussions.

\section{LITERATURE CITED}

Bao, J., Sharp, A. H., Wagster, M. V., Becher, M., Schilling, G., Ross, C. A., Dawson, V. L., and Dawson, T. M. 1996. Expansion of polyglutamine repeat in huntingtin leads to abnormal protein interactions involving calmodulin. Proc. Natl. Acad. Sci U.S.A. 93:5037-5042.

Bartnicki-Garcia, S., and Wang, M. C. 1983. Biochemical aspects of morphogenesis in Phytophthora. Pages 121-137 in: Phytophthora, Its Biology, Taxonomy, Ecology, and Pathology. D. C. Erwin, S. Bartnicki-Garcia, and P. H. Tsao, eds. American Phytopathological Society, St. Paul, MN, U.S.A.

Battaglia, D. E., and Shapiro, B. M. 1988. Hierarchies of protein crosslinking in the extracellular matrix: Involvement of an egg surface transglutaminase in early stages of fertilization envelope assembly. J. Cell Biol. 107:2447-2454.

Bech, L., Rasmussen, G., Halkier, T., Okada, M., Andersen, L. N., Kauppinen, M. S., and Sandal, T. August 2002. Transglutaminase from oomycetes. U.S. Patent 6,428,933.

Boller, T. 1995. Chemoperception of microbial signals in plant cells. Ann. Rev. Plant Phys. Plant Mol. Biol. 46:189-214.

Brunner, F., Rosahl, S., Lee, J., Rudd, J. J., Geiler, C., Kauppinen, S., Rasmussen, G., Scheel, D., and Nuernberger, T. 2002. Pep-13, a plant defense-inducing pathogen-associated pattern from Phytophthora transglutaminases. EMBO (Eur. Mol. Biol. Organ.) J 21:6681-6688.

Caten, C. E., and Jinks, J. L. 1968. Spontaneous variability in isolates of Phytophthora infestans. I. Cultural variation. Can. J. Bot. 46:329-348.

Ellis, J., Dodds, P., and Pryor, T. 2000. Structure, function and evolution of plant disease resistance genes. Curr. Opin. Plant Biol. 3:278-284.

Erwin, D. C., and Ribeiro, O. K. 1996. Phytophthora Diseases Worldwide. American Phytopathological Society, St. Paul, MN, U.S.A.

Fabritius, A.-L., Cvitanich, C., and Judelson, H. S. 2002. Stage-specific gene expression during sexual development in Phytophthora infestans. Mol. Microbiol. 45:1057-1066.

Felix, G., and Boller, T. 2003. Molecular sensing of bacteria in plants. The highly conserved RNA-binding motif RNP-1 of bacterial cold shock proteins is recognized as an elicitor signal in tobacco. J. Biol. Chem. 278:6201-6208.

Felix, G., Duran, J. D., Volko, S., and Boller, T. 1999. Plants have a sensitive perception system for the most conserved domain of bacterial flagellin. Plant J. 18:265-276.

Felsenstein, J. 1989. Phylip_-phylogeny inference package (version 3.2). Cladistics 5:164-166.

Filpula, D. R., Lee, S. M., Link, R. P., Strausberg, S. L., and Strausberg, R. L. 1990. Structural and functional repetition in a marine mussel adhesive protein. Biotechnol. Prog. 6:171-177.

Förster, H., and Coffey, M. D. 1990. Mating behavior of Phytophthora parasitica: Evidence for sexual recombination in oospores using DNA restriction fragment length polymorphisms as genetic markers. Exp. Mycol. 14:351-359.

Fosnaugh, K. L., and Loomis, W. F. 1989. Sequence of the Dictyostelium discoideum spore coat gene sp96. Nucleic Acids Res. 17:9489.

Gabriel, D. W. 1999. Why do pathogens carry avirulence genes? Phys. Mol. Plant Pathol. 55:205-214.

Görnhardt, B., Rouhara, I., and Schmelzer, E. 2000. Cyst germination proteins of the potato pathogen Phytophthora infestans share homology with human mucins. Mol. Plant-Microbe Interact. 13:32-42.

Goodwin, S. B., Smart, C. D., Sandrock, R. W., Deahl, K. L., Punja, Z. K., and Fry, W. E. 1998. Genetic change within populations of Phytophthora infestans in the United States and Canada during 1994 to 1996: Role of migration and recombination. Phytopathology 88:939949.

Groves, C. T., and Ristaino, J. B. 2000. Commercial fungicide formulations induce in vitro oospore formation and phenotypic change in mating type in Phytophthora infestans. Phytopathology 90:1201-1208. 
Hemmes, D., and Bartnicki-Garcia, S. 1975. Electron microscopy of gametangial interaction and oospore development in Phytophthora capsici. Arch. Microbiol. 103:91-112.

Judelson, H. S., and Roberts, S. 2002. Novel protein kinase induced during sporangial cleavage in the oomycete Phytophthora infestans. Euk. Cell 1:687-695.

Judelson, H. S., and Tooley, P. W. 2000. Enhanced polymerase chain reaction methods for detecting and quantifying Phytophthora infestans in plants. Phytopathology 90:1112-1119.

Kamoun, S., Van Der Lee, T., Van Der Berg-Velthuis, G., De Groot, K. E., and Govers, F. 1998. Loss of production of the elicitor protein INF1 in the clonal lineage US-1 of Phytophthora infestans. Phytopathology 88:1315-1323.

Keller, B., and Lamb, C. J. 1989. Specific expression of a novel cell wall hydroxyproline-rich glycoprotein gene in lateral root initiation. Genes Dev. 3:1639-1646.

Kirchner, J. W., and Roy, B. A. 2000. Evolutionary implications of hostpathogen specificity: The fitness consequences of host life history traits. Evol. Ecol. 14:665-692.

Klein, J. D., Guzman, E., and Kuehn, G. D. 1992. Purification and partial characterization of transglutaminase from Physarum polycephalum. J. Bacteriol. 174:2599-2605.

Lauge, R., and De Wit, P. J. G. M. 1998. Fungal avirulence genes: Structure and possible functions. Fungal Gen. Biol. 24:285-297.

Leal, J. A., Gallegly, M. E., and Lilly, V. G. 1967. The relation of the carbon-nitrogen ratio in the basal medium to sexual reproduction in species of Phytophthora. Mycologia 59:953-964.

Makarova, K. S., Aravind, L., and Koonin, E. V. 1999. A superfamily of archaeal, bacterial, and eukaryotic proteins homologous to animal transglutaminases. Prot. Sci. 8:1714-1719.

Nennstiel, D., Scheel, D., and Nuernberger, T. 1998. Characterization and partial purification of an oligopeptide elicitor receptor from parsley (Petroselinum crispum). FEBS (Fed. Eur. Biochem. Soc.) Lett. 431:405-410.

Nielsen, H., Engelbrecht, J., Brunak, S., and Von Heijne, G. 1997. Identification of prokaryotic and eukaryotic signal peptides and prediction of their cleavage sites. Prot. Eng. 10:1-6.

Nuernberger, T., and Brunner, F. 2002. Innate immunity in plants and animals: Emerging parallels between the recognition of general elicitors and pathogen-associated molecular patterns. Curr. Opin. Plant Biol. 5:318-324.

Nuernberger, T., Nennstiel, D., Jabs, T., Sacks, W. R., Hahlbrock, K., and Scheel, D. 1994. High affinity binding of a fungal oligopeptide elicitor to parsley plasma membranes triggers multiple defense responses. Cell 78:449-460.
Oyarzun, P. J., Pozo, A., Ordoñez, M. E., Doucett, K., and Forbes, G. A. 1998. Host specificity of Phytophthora infestans on tomato and potato in Ecuador. Phytopathology 88:265-271.

Ozinsky, A., Underhill David, M., Fontenot Jason, D., Hajjar Adeline, M. Smith Kelly, D., Wilson Christopher, B., Schroeder, L., and Aderem, A. 2000. The repertoire for pattern recognition of pathogens by the innate immune system is defined by cooperation between toll-like receptors. Proc. Nat. Acad. Sci. U.S.A. 97:13766-13771.

Parker, J. E., Hahlbrock, K., and Scheel, D. 1988. Different cell wall components from Phytophthora megasperma f. sp. glycinea elicit phytoalexin production in soybean and parsley. Planta 176:75-82.

Pieterse, C. M. J., Van West, P., Verbakel, H. M., Brasse, P. W. H. M., Van Den Berg-Velthuis, G. C. M., and Govers, F. 1994. Structure and genomic organization of the $\mathrm{ipiB}$ and $\mathrm{ipiO}$ gene clusters of Phytophthora infestans. Gene 138:67-77.

Ponchet, M., Panabieres, F., Milat, M. L., Mikes, V., Montillet, J. L. Suty, L., Triantaphylides, C., Tirilly, Y., and Blein, J. P. 1999. Are elicitins cryptograms in plant-oomycete communications? CMLS Cell Mol. Life Sci. 56:1020-1047.

Pryor, T. 1987. The origin and structure of fungal disease resistance genes in plants. Trends Genet. 3:157-161.

Sacks, W., Nuernberger, T., Hahlbrock, K., and Scheel, D. 1995. Molecular characterization of nucleotide sequences encoding the extracellular glycoprotein elicitor from Phytophthora megasperma. Mol. Gen. Genet. 246:45-55.

Shimony, C., and Friend, J. 1975. Ultrastructure of the interaction between Phytophthora infestans and leaves of two cultivars of potato Solanum tuberosum, Orion and Majestic. New Phytol. 74:59-65.

Smythe, J. A., Peterson, M. G., Coppel, R. L., Saul, A. J., Kemp, D. J., and Anders, R. F. 1990. Structural diversity in the 45-kilodalton merozoite surface antigen of Plasmodium falciparum. Mol. Biochem. Parasit. 39:227-234.

Spiro, R. G. 2002. Protein glycosylation: Nature, distribution, enzymatic formation, and disease implications of glycopeptide bonds. Glycobiology 12:43R-56R.

Van Kan, J. A. L., Van Den Ackerveken, G. F. J. M., and De Wit, P. J. G. M. 1991. Cloning and characterization of complementary DNA of avirulence gene avr9 of the fungal pathogen Cladosporium fulvum causal agent of tomato leaf mold. Mol. Plant-Microbe Interact. 4:52-59.

Vivian, A., and Gibbon, M. J. 1997. Avirulence genes in plant-pathogenic bacteria: Signals or weapons? Microbiology 143:693-704.

Waffenschmidt, S., Kusch, T., and Woessner, J. P. 1999. A transglutaminase immunologically related to tissue transglutaminase catalyzes cross-linking of cell wall proteins in Chlamydomonas reinhardtii. Plant Phys. 121:1003-1015. 